\title{
The IIASA-VID reconstructions and projections of educational attainment by age and sex for 120 countries, 1970-2000 New Data on Human Capital
}

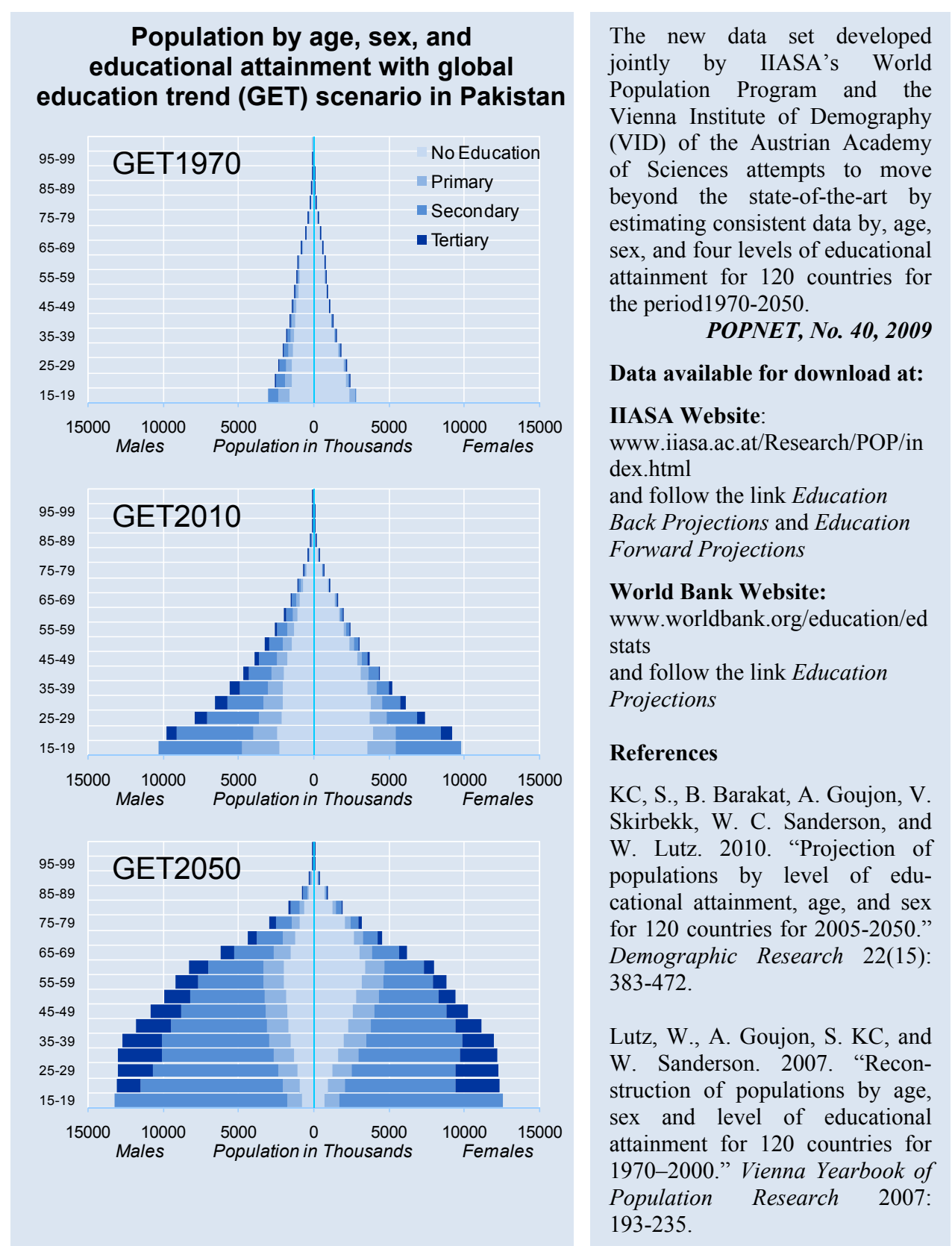

